\title{
Genetics of Adult Onset Stroke Subtypes: A Review of Current Knowldege and Future Prospects
}

\author{
Muhammad Sougatul Islam¹, Bitali Islam², Munia Amin³, A T M Hasibul Hasan \\ ${ }^{1}$ Executive Director, BioTED, Dhaka, Bangladesh; ${ }^{2}$ Research Assitant, BioTED, Dhaka, Bangladesh; ${ }^{3}$ Senior \\ Research Fellow, BioTED, Dhaka, Bangladesh; ${ }^{4}$ Assistant Professor, Department of Interventional \\ Neurology, National Institute of Neurosciences and Hospital, Dhaka, Bangladesh
}

[Received on: 22 November 2020; Accepted on: 12 December 2020; Published: 1 January 2021]

\begin{abstract}
The genetic contribution in stroke onset depends on the stroke subtypes. Understanding the genetic mechanism may influence the future direction in stroke management. There is complex interplay of genetic and environmental factors for any stroke event. Very small proportion of stroke is attributable to mendelian disorders. Stroke may also manifest as part of a syndromic disease in the form of single gene multisystem disorder. But there is no direct contribution of genetic polymorphism in conventional stroke subtypes. Specific genetic loci increase the suspectibility to development of hypertension, diabetes, dyslipideamia or influence the coagulation pathway or chance of atheroma formation and embolism. While chr9p21 locus or PITX2 and ZFHX3 are related to cardioemetabolic, HDAC9, TSPAN2 and 9p21 locus are responsible for the large vessel occlusion. On the otherhand, genome-wide significant locus on chromosome 1q22 the APOE locus are found to have significant association with intracerebral hemorrhage. But the direct pathophysiologic relationship of genetic plymorphirsm may be linked to onset of sub arachnoid hemorrhage. MMP-3, endothelial nitric oxide synthase (eNOS), tumor necrosis factor (TNF)- $\alpha$, VCAM-1 etc have been found to be responsible for intracranial aneurysm formation, growth and risk of rupture. [Journal of National Institute of Neurosciences Bangladesh, January 2021;7(1): 79-86]
\end{abstract}

Keywords: : Extradural haematoma; traumatic head injury; road traffic accident; assault

Correspondence: Dr. ATM Hasibul Hasan, Assistant Professor, Department of Interventional Neurology, National Institute of Neurosciences and Hospital, Sher-E-Bangla Nagar, Agargaon, Dhaka, Bangladesh; Email: parag007us@gmail.com; Cell no.: $+8801763498663$

Conflict of interest: There is no financial conflict of interest relevant to this paper to disclose.

Contribution to authors: All authors were involved from literature serach upto manuscript writing.

How to cite this article: Islam MS, Islam B, Amin M, Hasan ATMH. Genetics of Adult Onset Stroke Subtypes: A Review of Current Knowldege and Future Prospects. J Natl Inst Neurosci Bangladesh, 2021;7(1): 79-86

Copyright: (C2021. Islam et al. Published by Journal of National Institute of Neurosciences Bangladesh. This article is published under the Creative Commons CC BY-NC License (https://creativecommons.org/licenses/by-nc/4.0/). This license permits use, distribution and reproduction in any medium, provided the original work is properly cited, and is not used for commercial purposes.

\section{Introduction}

Stroke is defined as a focal (or at times global) neurological impairment of sudden onset, lasting more than $24 \mathrm{~h}$ (or leading to death) and of presumed vascular origin $^{1}$. An estimated 16.3 million people around the world suffer from stroke each year of which 11.2 million events occur in developing countries. Annually 5.8 million people die of stroke, the two third of which occurs in developing countries ${ }^{2}$. Another 64.5 million stroke patients survives an acute stroke event and live with varying degree of disability, which have made the disease the leading cause of morbidity ${ }^{2}$. The World Bank also reported that non-communicable diseases (NCDs) were responsible for almost two-thirds (63\%) of Disability-adjusted life years (DALYs) in Bangladesh in 2016, while the contribution of communicable, maternal, neonatal and nutritional diseases accounted for $27 \%$ and injuries for $11 \%$ of DALYs ${ }^{3}$. According to the report, Ischemic heart disease (IHD), stroke and type 2 diabetes were the main contributors to the NCD burden. The Household Income and Expenditure Survey (HIES) done in the same year also reported that HTN, chronic heart disease and diabetes were among the most prevalent illnesses ${ }^{3}$. 
The geographic variations observed in stroke prevalence and mortality data can be attributed to difference of risk factor prevalence, genetic susceptibility and level of healthcare facilities. The INTERSTROKE case control study has provided the most reliable data on stroke risk factors in developing countries. Hypertension, current smoking, abdominal obesity, low physical activity and unhealthy cardiovascular diet accounted for the $80 \%$ of the risk of all type of stroke ${ }^{4}$. Meta-analysis of risk factors among the population in Bangladesh reported a prevalence of $14 \%$ for hypertension and $6 \%$ for diabetes $^{3}$. Bangladesh is ranked among the top 10 countries with the highest number of people living with diabetes $^{3}$. The lifetime risk of stroke has been estimated at one in five for middle-aged women and one in six for middle-aged men in the Framingham Heart Study 5 .

Beside the known common risk factors a substantial proportion of stroke risk remains unexplained. Henceforth, a contribution of genetic factors are acknowledged by recent reports of common genetic variation associated with stroke risk through the genome-wide association studies (GWAS) ${ }^{6}$. Over the last decade we have observed a significant progress in unravelling the basis of single gene stroke disorders. But it has always been difficult to identify the underlying genes for common or multifactorial stroke, for which there is no obvious Mendelian pattern of inheritance is proven. In stroke genetics there are several focuses of clinical interest, for example, molecular genetic variations affecting risk of monogenic stroke syndromes and common stroke syndrome, epigenetic impact on protein expression during acute brain injury, the association of genetics with the stroke risk factor, genetic influence on stroke recovery, hereditary causes of familial aggregation, and pharmacogenetics? In this review we have tried to accumulate the genetic basis of both single gene disorders causing rare type of stroke and the common conventional multifactorial stroke subtypes.

\section{Genetic Risk of Stroke}

People often wonder, is stroke heritable? The answer comes mostly from twin studies. The risk of stroke is 1.65 times higher in monozygotic twins ${ }^{7}$. Though insignificant in small vessel disease, genome-wide SNP data suggests similar heritability for cardioembolic and large vessel occlusions ${ }^{8}$. Several other factors like age, sex and stroke subtypes may also modify the relationship. Yonger patients and women are more likely to have a first degree relative suffering such event $t^{9,10}$. The contribution of hereditary factor as a risk of stroke remains complex. Influnce of conventional risk factors, variations in vulnerability of stroke among population along with heterogenicity of stroke subtypes have made the situation worse. Genetic risk of stroke may be explained by several proposed mechanisms. Firstly, single gene disorders, though rare, contributes to familial stroke syndromes like cerebral autosomal dominant arteriopathy with subcortical infarct and leukoencephalopathy (CADASIL). Secondly, there are some single gene disorder that casue multisystem disease like sickle cell anemia which sometimes may present with stroke in course of time. Thirdly, conventional stroke risk factors may also have underlying genetic basis. Moreover, genetic polymorphisms had been linked to risk of stroke ${ }^{11}$.

\section{Single Gene Disorder Presenting Primarily as Stroke}

The most common example of this entity is CADASIL which is a small vessel vasculopathy affecting central nervous system and skin. The disease is linked mostly to missense mutation in the Notch 3 gene on chromosome $19 \mathrm{q} 12$ which leads to alteration in cysteine residue expressed on extracellular receptors ${ }^{12,13}$. Although granular eosinophilic material on skin biopsy may be pathonomognic, patients may have negative result for common mutations ${ }^{14,15}$. There are several other rare single gene mutations implicated in stroke aetiology. For example, HTRA serine peptidase-1 gene for cerebral autosomal recessive arteriopathy with subcortical infarct and leukoencephalopathy (CARASIL), SLC2A10 gene for arterial tortiousity syndrome and cystatin $\mathrm{C}$ mutation causing familial cerebral amayloid angiopathy ${ }^{16-19}$. Monogenic disorders associated with stroke and their pattern of inheritance are summarized in table 1.

\section{Single gene multisystem disorder associated with stroke}

There are several single gene disorders where cerebrovascular events may occure as an important manifestation of disease. Around $25 \%$ of the patients with sickle cell anemia may experience ischemic stroke by the age of 45 years 19. Polymerization of red blood cells in low oxygen tension may lead to recurrent event, some of which may be clinically silent ${ }^{20,21}$. The X-linked Fabry disease, the second most common lysosomal storage disorder is caused by a missense or nonsense mutation in GLA gene. This typically involves young patients affecting both small and large vessel in posterior circulation $^{22}$. Mutation in mitochondrial gene may also lead to stroke like episodes. The syndrome of mitochondrial encephalopathy, lactic acidosis, and stroke like episode (MELAS) caused mostly by an A3243G 
Table 1: Monogenic disorder associated with stroke $\mathrm{e}^{12-19}$

\begin{tabular}{|c|c|c|}
\hline Disease & onsible Gene/chromosomal location & Inheritance Mood \\
\hline \multirow[t]{2}{*}{ CADASIL } & $\mathrm{NOTCH} 3$ & autosomal dominant \\
\hline & $19 \mathrm{p} 13.2-\mathrm{p} 13.1$ & \\
\hline \multirow[t]{2}{*}{ CARASIL } & HTRA1 & autosomal recessive \\
\hline & $10 \mathrm{q} 26.3$ & \\
\hline \multirow[t]{2}{*}{ RVCL } & TREX1 & autosomal dominant \\
\hline & $3 \mathrm{p} 21.3$ & \\
\hline CRV and HERNS & $3 \mathrm{p} 21.1-21.3$ & autosomal dominant \\
\hline \multirow[t]{2}{*}{ Sickle cell disease } & HBB, Haemoglobin S, and SC & autosomal recessive \\
\hline & $11 \mathrm{p} 15.5$ & \\
\hline \multirow[t]{3}{*}{ Homocystinuria } & CBS, MTHFR, and other & autosomal recessive \\
\hline & $21 \mathrm{q} 22.3,1 \mathrm{p} 36.3$ & \\
\hline & and other & \\
\hline \multirow[t]{2}{*}{ Fabry disease } & alpha-galactosidase A gene & X-linked \\
\hline & X chromosome & \\
\hline \multirow[t]{2}{*}{ PXE } & ABCC6 & \\
\hline & $16 \mathrm{p} 13.1$ & autosomal recessive \\
\hline Dyslipidaemias & ABHD5 mutations and others & autosomal dominant \\
\hline Moyamoya disease & $3 \mathrm{p} 24.2-26$ and $17 \mathrm{q} 25$ & autosomal dominant \\
\hline \multirow[t]{2}{*}{ Neurofibromatosis type I } & NFI gene & autosomal dominant \\
\hline & $17 q 11.2$ & \\
\hline Vascular EDS & COL3A1 & autosomal dominant \\
\hline \multirow[t]{2}{*}{ Marfan syndrome } & FBN1 & autosomal dominant \\
\hline & $15 q 21.1$ & \\
\hline \multirow[t]{2}{*}{ MELAS } & tRNA Leu & maternal inheritance \\
\hline & Mitochondrial DNA & \\
\hline \multirow[t]{3}{*}{ CAA } & APP, CST3 & autosomal dominant \\
\hline & $21 \mathrm{q} 21.3$ & \\
\hline & and other & \\
\hline \multirow[t]{2}{*}{ COL4A1 syndrome } & COL4A1 & autosomal dominant \\
\hline & $13 q 34$ & \\
\hline Protein C, S & Protein $\mathrm{S}$ and $\mathrm{C}$ genes & autosomal dominant \\
\hline Antithrombin III deficiency & Antithrombin III gene & autosomal dominant \\
\hline Familial anticardiolipin syndrome & Unknown & autosomal dominant \\
\hline Activated protein $\mathrm{C}$ resistance & Factor V Leiden mutation & autosomal dominant \\
\hline \multirow[t]{2}{*}{ Ehlers-Danlos syndrome type IV } & collagen type III gene & autosomal dominant \\
\hline & $2 q 31$ & \\
\hline Fibromuscular dysplasia & Unknown & autosomal dominant \\
\hline \multirow[t]{2}{*}{ von Hippel-Lindau syndrome } & VHL & autosomal dominant \\
\hline & $3 \mathrm{p} 25.3$ & \\
\hline
\end{tabular}

CADASIL = cerebral autosomal dominant arteriopathy with subcortical infarcts and leukoencephalopathy; CARASIL= Cerebral autosomal recessive arteriopathy with subcortical infarcts and leukoencephalopathy; RVCL $=$ Retinal vasculopathy with cerebral leukodystrophy; CRV= Cerebroretinal vasculopathy; HERNS= Hereditary endotheliopathy, retinopathy, nephropathy, and stroke; $\mathrm{PXE}=$ Pseudoxanthoma elasticum; Vascular EDS= Vascular Ehlers-Danlos syndrome; MELAS= Mitochondrial Encephalopathy, Lactic Acidosis, and Stroke-like episodes; CAA= Cerebral amyloid angiopathy; COL4A1 = Collagen alpha-1(IV) chain

substitution within tRNA gene ${ }^{23}$. Stroke like episodes may be observed in MELAS but the pathogenesis is mainly metabolic rather than vasooclussive ${ }^{23}$. Genetic disorders of collegen tissue may also affect cerebral vasculature. Mutation in Type-III collagen involving COL3A1 or COL4A1 leads to vascular fragility causing 
arterial dissection or aneurysm formation ${ }^{24}$. Marfan syndrome and ACTA2 associated vasculopathy also manifests with stroke in similar mechanism ${ }^{25}$. They also increase the risk of aretial dissection, moyamoya disease, aneurysm formation and also even in small vessel disease $^{26}$.

\section{Genes Responsible for Common Conventional Multifactorial Stroke Subtypes}

Genetic Contribution in Ischemic Stroke: Understanding the genetics behind the common pattern of stroke is more important in respect to clinical practice and practical point of view. Genetic predisposition to common stroke subtypes does not act directly. There are several mechanisms, for example; increasing the susceptibility to common risk factors like hypertension or diabetes, by influencing mechanism of stroke e.g. atheroma or atrial fibrillation, altering coagulation pathways and by influencing tolerance to ischemic injury ${ }^{27}$. The largest effort to identify the genetic mutation was MetaStroke that involved case control studies from 15 countries in Europe, North America and Australia. They found a gene variant that is related to blood group (rs505922), mostly associated with large vessel occlusion and cardio-embolic stroke ${ }^{28}$. The chr9p21 locus or the ABO locus on chromosome 9 was found to be responsible. Moreover, PITX2 and ZFHX3 were found to be related to cardioemetabolic and HDAC9, TSPAN2 and 9p21 locus to the large vessel occlusion ${ }^{29}$. Studies determining the genetic influence of small vessel occlusion had not been uniform in phenotypic definition of small artery occlusion. Genetic contribution in small vessel occlusion also varies across the ethnicity. The association of PRKCH gene with small vessel stroke was only found in the Japanese and Chinese population, but not in Europeans ${ }^{30-33}$. Genome-wide association studies (GWAS) also identified a locus on 6p25 (rs $12204590)$ that is associed with small vessel disease and manifests either as stroke event of white matter hyperintensity on imaging studies $^{34}$. Forkhead transcription factor gene FOXF2 located nearby is also associed with extensive white matter disease in young if deleted $^{35}$. Moreover, several gene locus and single neucleotide polymorphism (SNP) had been found associated with ischemic stroke irrespective of stroke subtypes. The chr12q24.12, SH2B3, ALDH2 HABP2 and AQP9 has been attributed ${ }^{36-40}$. Another risk loci was identified by CADISP consortium for carotid artery dissection in young stroke patients. They suggested that PHACTR1 expressed in certain tissue may play a majore role in vascular tube formation and actin polymerization ${ }^{41}$.

Genetic Risk for Conventional Intracerebral Hemorrhage (ICH): The genetic pattern differ for subtypes of ICH as well. The recent discovery of a genome-wide significant locus on chromosome 1q22 by the International Stroke Genetics Consortium has put a new light to pathogenesis of common non-lobar intra cerebral hemorrhages. The same locus was also reported to be associated with white matter hyperintensity burden ${ }^{42}$. Moreover in a larger candidate gene study the APOE locus was found to have significant association with ICH. The APOE2 and APOE4 had genome wide significant association with lobar hemorrhage ${ }^{43}$.

Genetic Background of Aneurysmal Subarachnoid Hemorrhage (SAH): People having the first-degree relative with aneurysm are at higher risk to develop aneurysm ${ }^{44,45}$. Different studies showed that MMP-3 (matrix metalloproteinases-3) plays a crucial role in aneurysm formation by activating several other pro-MMPs ${ }^{46}$. Ehlers-Danlos syndrome (EDS) type II and IV, Marfan syndrome, neurofibromatosis type I (NF-1), multiple endocrine neoplasia type I, pseudoxanthoma elasticum, hereditary hemorrhagic telangiectasia, all these heritable connective-tissue disorders support a genetic contribution to cerebral aneurysms (CA) $)^{46-49}$. TIMP-1 and TIMP-2 (tissue inhibitor of matrix metalloproteinase) play a critical role in preventing the CA progression ${ }^{50}$. Genes that are responsible for maintaining the extracellular matrix are associated with intracranial aneurysm (IA ${ }^{51}$. Single-nucleotide polymorphisms (SNPs) in the endothelial nitric oxide synthase (eNOS) gene contribute to the IA formation and progression. The elevated level of IL-6 in the plasma contributes to the pathogenesis of IA. They release adhesion molecules and chemokine, which eventually cause endothelial dysfunction $^{52}$. Studies showed the association of apoptosis and inflammatory response with IA development. Researchers found the presence of various cytokines expression and macrophage infiltration in human IAs. Upregulation of tumor necrosis factor (TNF)- $\alpha, \mathrm{C}-\mathrm{X}-\mathrm{C}$ chemokine receptor type 4 (CXCR4), interleukin (IL)-1 $\beta$, molecule (VCAM)-1, vascular cell adhesion, and chemokine ligand (CCL) 5 have been seen in human IA walls ${ }^{53}$. In IA formation, nuclear factor (NF)- $\mathrm{kB}$ contributes as a transcription factor ${ }^{54}$. The chromosomal location associated with aneurysm formation and progression have been summarized in Table 2. 
Table 2: List of Chromosomal Location Associated With Aneurysm Formation And Progression

\begin{tabular}{lc}
\hline Chromosome region & Outcome \\
\hline $1 \mathrm{p} 34.3-\mathrm{p} 36.13^{55}$ & Confirmed linkage \\
$7 \mathrm{q} 11^{56-58}$ & Confirmed linkage \\
$19 \mathrm{q} 13.3^{59}$ & Confirmed linkage \\
Xp2259, & Confirmed linkage \\
$5 \mathrm{q} 22-31^{57,58,60}$ & Evidence of linkage \\
$19 \mathrm{q} 13^{60}$ & Confirmed linkage \\
$14 \mathrm{q} 22^{57}$ & Evidence of linkage \\
$5 \mathrm{q} 31^{61,62}$ & Association with FGF1 \\
$8 \mathrm{p} 21^{63}$ & Linkage to LOXL2 gene \\
$14 \mathrm{q} 23^{64}$ & Evidence of association \\
$19 \mathrm{q} 12-13^{65}$ & Evidence of predisposing genes \\
$14 \mathrm{q} 23-31^{66}$ & Confirmed linkage \\
$11 \mathrm{q} 24-25^{66}$ & Confirmed linkage \\
$4 \mathrm{q} 32^{67}$ & Confirmed linkage \\
$8 \mathrm{q} 12.1^{67,68}$ & Confirmed linkage to SOX17 gene \\
$9 \mathrm{p} 21^{68-71}$ & Confirmed linkage to CDKN2A, \\
$7 \mathrm{p} 21-15^{72}$ & CDKN2B, and CDKN2BAS genes \\
$7 \mathrm{q} 35-36^{72}$ & Confirmed linkage to IL-6 gene \\
$10 \mathrm{q} 24.32^{73}$ & Confirmed linkage to eNOS gene \\
$13 \mathrm{q} 13.1^{73}$ & Confirmed linkage to CNNM2 gene \\
$18 \mathrm{q} 11.2^{73}$ & Confirmed linkage to STARD13-KL gene \\
\hline
\end{tabular}

FGF1 = fibroblast growth factor 1; FBN2 = fibrillin 2; LOX = lysyl oxidase; LOXL = lysyl oxidase-like; IL-6 = interleukin 6; eNOS = endothelial nitric oxide synthase

\section{Importance of Stroke Genetics}

Stroke should be thought of as a clinical syndrome, not a single disease which can be caused by several different pathologies. There are pieces of evidence of genetic associations with various diseases that are associated with stroke (Table 1). Gene-environment interactions can play an important role in stroke pathogenesis ${ }^{74}$. In a study with 200 consecutively recruited CADASIL individuals showed the association of conventional cardiovascular risk factors, predominantly hypertension, and smoking with an earlier age of stroke onset, which gives significant insight in the importance of gene-environmental interactions as well as careful risk factor control in individuals with monogenic stroke disorders, for example, CADASIL ${ }^{75}$. A number of studies shown significant findings in identifying genes for multifactorial stroke. Future srudies with a large number of sample are required to detect the genetic risk factors of stroke. Genetic predisposition to stroke is supported by epidemiologic evidence. Stroke genetics will help to get a better insight into how some individuals with the same risk factor profiles remain stroke-free, whereas others develop stroke. These types of studies may help to find novel stroke mechanisms and suggest new treatment approaches. The majority of stroke is polygenic. Monogenic stroke is rare. In many rare monogenic diseases, exome sequencing has been successful ${ }^{76}$. To screen for multiple single-gene causes of stroke, exome sequencing may offer a cost-effective way in one assay. Detecting the responsible gene for monogenic stroke might be used to diagnose and intervene in some cases. The risk of drug-related adverse effects and drug efficacy is affected by genetic variations. An individual's genotype can be used for determining the optimal dose with maximum efficacy with minimal adverse effects ${ }^{77}$. Stroke genomics can help in understanding new mechanisms underlying drug action. This understanding will lead to the development of new therapeutic agents. Stroke genetics can provide insights into the educated prediction of risks. Educated prediction enables counseling of individual, and prenatal testing whenever requirement. The possibility and degree of the functional outcome as well as the responses to therapies after stroke can vary between patients due to underlying genetic variations.

\section{Method of Identifying Genes Responsible for Stroke}

To identify genes for stroke three main methods have been used like linkage analysis, the candidate gene approach, genome-wide association studies (GWAS). The linkage method is used to find the association of chromosomal markers with disease phenotype within families. Genes associated with high risk can be successfully detected by this method. This technique has been used to find many disease-causing genes, predominantly single-gene disorders. Linkage is less successful in more common polygenic diseases. The candidate gene method was used to look for genes predisposing to common stroke. In this method a candidate gene is selected, which is thought to be involved in stroke risk, followed by identification of genetic variants, usually single-nucleotide polymorphisms (SNPs) for that candidate gene. After that using a case-control approach frequency of the SNP is compared between controls and stroke patients. Novel genes cannot be identified by candidate-gene studies. Recently, GWAS is mostly used in the field of complex stroke genetics. This technique uses microarray technology to genotype more than one million SNPs, spanning the whole genome. The frequency of individual SNPs between controls and disease cases is compared by cohort or case-control 
approach. Associations between novel chromosomal loci and disease can be identified by $\mathrm{GWAS}^{76}$. Application of next generataion sequencing (NGS) along with existing method is expected to facilitate the process of gene discovery in near future.

\section{Conclusion}

Researchers found common genetic variants associated with stroke, which helps us to get a better insight into the underlying pathophysiology. Identification and understanding of single-gene disorders associated with stroke have substantially broadened our knowledge, nevertheless we do not have a clear understanding of the genetic factors influencing polygenic and multifactorial stroke. Future studies should focus on identifying potential interactions among various genetic and environmental factors of polygenic stroke, which will lead to development of new drugs as part of precision medicine approach. As we know from various studies, different forms of stroke are affected by genetic factors in different ways. Therefore, studies of large sample size on individual stroke subtypes must be conducted get a better understanding about the genetic factors driving stroke outcome.

\section{References}

1. World Health Organization. The WHO STEPwise approach to stroke surveillance. Geneva: WHO, 2005.

2. Strong K, Mathers C, Bonita R. Preventing stroke: saving lives around the world. Lancet Neurol 2007; 6: 182-87.

3. Hypertension and type-2 diabetes in Bangladesh: Continuum of Care Assessment and Opportunities for Action. The World Bank, June 2019.

4. Feigin VL, Krishnamurthi R. Stroke Prevention in the Developing World. Stroke. 2011;42:3655-3658.

5. Seshadri S, Wolf PA. Lifetime risk of stroke and dementia: current concepts, and estimates from the Framingham Study. Lancet Neurol. 2007;6:1106-14.

6. Falcone GJ, Malik R, Dichgans M, Rosand J. Current concepts and clinical applications of stroke genetics. Lancet Neurol. 2014;13:405-18.

7. Flossmann E, Schulz UG, Rothwell PM. Systematic review of methods and results of studies of the genetic epidemiology of ischemic stroke. Stroke. 2004;35:212-227.

8. Bevan S, Traylor M, Adib-Samii P, Malik R, Paul NL, Jackson C, Farrall M, Rothwell PM, Sudlow C, Dichgans M, Markus HS. Genetic heritability of ischemic stroke and the contribution of previously reported candidate gene and genomewide associations. Stroke. 2012;43:3161-3167.

9. Schulz UG, Flossmann E, Rothwell PM. Heritability of ischemic stroke in relation to age, vascular risk factors, and subtypes of incident stroke in population-based studies. Stroke. 2004;35:819-824.

10. Touzé E, Rothwell PM. Sex differences in heritability of ischemic stroke: a systematic review and meta-analysis. Stroke. 2008;39:16-23.

11. Matarin M, Brown WM, Singleton A, Hardy JA, Meschia JF;
ISGS investigators. Whole genome analyses suggest ischemic stroke and heart disease share an association with polymorphisms on chromosome 9p21. Stroke. 2008;39:1586-1589.

12. Tournier-Lasserve E, Iba-Zizen MT, Romero N, Bousser MG. Autosomal dominant syndrome with strokelike episodes and leukoencephalopathy. Stroke. 1991;22:1297-1302.

13. Peters N, Opherk C, Bergmann T, Castro M, Herzog J, Dichgans M. Spectrum of mutations in biopsy-proven CADASIL: implications for diagnostic strategies. Arch Neurol. 2005;62:1091-1094.

14. Joutel A, Andreux F, Gaulis S, Domenga V, Cecillon M, Battail N, Piga N, Chapon F, Godfrain C, Tournier-Lasserve E. The ectodomain of the Notch3 receptor accumulates within the cerebrovasculature of CADASIL patients. J Clin Invest. 2000;105:597-605.

15. Ebke M, Dichgans M, Bergmann M, Voelter HU, Rieger P, Gasser T, Schwendemann G. CADASIL: skin biopsy allows diagnosis in early stages. Acta Neurol Scand. 1997;95:351-357.

16. Menezes Cordeiro I, Nzwalo H, Sá F, Ferreira RB, Alonso I, Afonso L, Basílio C. Shifting the CARASIL paradigm: report of a non-Asian family and literature review. Stroke. 2015;46:1110-1112.

17. Hara K, Shiga A, Fukutake T, et al. Association of HTRA1 mutations and familial ischemic cerebral small-vessel disease. $\mathrm{N}$ Engl J Med. 2009;360:1729-1739. doi: 10.1056/NEJMoa0801560. 18. Annes JP, Munger JS, Rifkin DB. Making sense of latent TGFbeta activation. J Cell Sci. 2003;116:217-224.

19. Ohene-Frempong K, Weiner SJ, Sleeper LA et al. Cerebrovascular accidents in sickle cell disease: rates and risk factors. Blood. 1998;91:288-294.

20. Russell MO, Goldberg HI, Hodson A et al. Effect of transfusion therapy on arteriographic abnormalities and on recurrence of stroke in sickle cell disease. Blood. 1984;63:162-

21. Schatz J, Brown RT, Pascual JM et al. Poor school and cognitive functioning with silent cerebral infarcts and sickle cell disease. Neurology. 2001;56:1109-1111.

22. Dichgans M. Genetics of ischaemic stroke. Lancet Neurol. 2007;6:149- 161 .

23. Martínez-Fernández E, Gil-Peralta A, García-Lozano R et al. Mitochondrial disease and stroke. Stroke. 2001;32:2507-2510.

24. Gould DB, Phalan FC, van Mil SE et al. Role of COL4A1 in small-vessel disease and hemorrhagic stroke. N Engl J Med. 2006;354:1489-1496. doi: 10.1056/NEJMoa053727.

25. Milewicz DM, Østergaard JR, Ala-Kokko LM et al. De novo ACTA2 mutation causes a novel syndrome of multisystemic smooth muscle dysfunction.

26. Munot P, Saunders DE, Milewicz DM, Regalado ES et al. A novel distinctive cerebrovascular phenotype is associated with heterozygous Arg179 ACTA2 mutations. Brain. 2012;135:2506-2514. doi: 10.1093/brain/aws172.

27. Hassan A, Markus HS. Genetics and ischaemic stroke. Brain. 2000;123(Pt 9):1784-812.

28. Gretarsdottir S, Thorleifsson G, Manolescu A, et al. Risk variants for atrial fibrillation on chromosome 4q25 associate with ischemic stroke. Ann Neurol. 2008;64:402-409.

29. Network NSG, International Stroke Genetics C. Loci associated with ischaemic stroke and its subtypes (sign): a genome-wide association study. Lancet Neurol. 2016; 15(2): 174-184.

30. Traylor M, Farrall M, Holliday EG, et al. Genetic risk factors for ischaemic stroke and its subtypes (the METASTROKE Collaboration): a meta-analysis of genome-wide association studies. Lancet Neurol. 2012;11:951-62.

31. Wu L, Shen Y, Liu X, et al. The 1425G/A SNP in PRKCH is 
associated with ischemic stroke and cerebral hemorrhage in a Chinese population. Stroke. 2009;40:2973-6.

32. Serizawa M, Nabika T, Ochiai Y, et al. Association between PRKCH gene polymorphisms and subcortical silent brain infarction. Atherosclerosis. 2008;199:340-5.

33. Kubo M, Hata J, Ninomiya T, et al. A nonsynonymous SNP in PRKCH (protein kinase $\mathrm{C}$ eta) increases the risk of cerebral infarction. Nat Genet. 2007;39:212-7.

34. Neurology Working Group of the Cohorts for Heart and Aging Research in Genomic Epidemiology (CHARGE) Consortium; Stroke Genetics Network (SiGN); International Stroke Genetics Consortium (ISGC). Identification of additional risk loci for stroke and small vessel disease: a meta-analysis of genome-wide association studies. Lancet Neurol. 2016;15:695-707.

35. French CR, Seshadri S, Destefano AL, et al. Mutation of FOXC1 and PITX2 induces cerebral small-vessel disease. J Clin Invest. 2014;124:4877-4881. doi: 10.1172/JCI75109.

36. Kilarski LL, Achterberg S, Devan WJ, et al. Meta-analysis in more than 17,900 cases of ischemic stroke reveals a novel association at 12q24.12. Neurology. 2014;83:678-85.

37. Malik R, Traylor M, Pulit SL, et al. Low-frequency and common genetic variation in ischemic stroke: the METASTROKE collaboration. Neurology. 2016;86:1217-26.

38. Cheng YC, Stanne TM, Giese AK, et al. Genome-wide association analysis of young-onset stroke identifies a locus on chromosome 10q25 Near HABP2. Stroke. 2016;47:307-16.

39. Ehret GB, Munroe PB, Rice KM, et al. Genetic variants in novel pathways influence blood pressure and cardiovascular disease risk. Nature. 2011;478:103-9.

40. Wain LV, Verwoert GC, O'Reilly PF, et al. Genome-wide association study identifies six new loci influencing pulse pressure and mean arterial pressure. Nat Genet. 2011;43:1005-11.

41. Debette S, Kamatani Y, Metso TM, et al. Common variation in PHACTR1 is associated with susceptibility to cervical artery dissection. Nat Genet. 2015;47:78-83.

42. Woo D, Falcone GJ, Devan WJ, et al. Meta-analysis of Genome-wide Association Studies Identifies $1 \mathrm{q} 22$ as a Susceptibility Locus for Intracerebral Hemorrhage. Am J Hum Genet. 2014;94:511-21.

43. Biffi A, Sonni A, Anderson CD, et al. Variants at APOE influence risk of deep and lobar intracerebral hemorrhage. Ann Neurol. 2010;68:934-43.

44. Sacco RL, Wolf PA, Bharucha NE et al. Subarachnoid and intracerebral hemorrhage: natural history, prognosis, and precursive factors in the Framingham Study. Neurology 2014; 34(7):847-847.

45. Krex D, Schackert HK, Schackert G. Genesis of cerebral aneurysms-an update. Acta neurochirurgica, 2001; 143(5): 429-449.

46. Silence J, Lupu F, Collen D, Lijnen HR. Persistence of atherosclerotic plaque but reduced aneurysm formation in mice with stromelysin-1 (MMP-3) gene inactivation. Arteriosclerosis, thrombosis, and vascular biology, 2001; 21(9): 1440-1445.

47. Jakubowski J, Kendall B. Coincidental aneurysms with tumours of pituitary origin. Journal of Neurology, Neurosurgery \& Psychiatry. 1978; 41(11): 972-979.

48. Maher CO, Piepgras DG, Brown Jr et al. Cerebrovascular manifestations in 321 cases of hereditary hemorrhagic telangiectasia. Stroke 2001; 32(4): 877-882.

49. Grond-Ginsbach, C, Schnippering H, Hausser I, et al. Ultrastructural connective tissue aberrations in patients with intracranial aneurysms. Stroke, 2002; 33(9): 2192-2196.

50. Aoki T, Kataoka H, Moriwaki T, Nozaki K, Hashimoto N. Role of TIMP-1 and TIMP-2 in the progression of cerebral aneurysms.
Stroke 2007; 38(8): 2337-2345.

51. Krischek B, \& Inoue I. The genetics of intracranial aneurysms. Journal of human genetics 2006; 51(7): 587-594.

52. Caranci F, Briganti F, Cirillo L, Leonardi M, Muto M. Epidemiology and genetics of intracranial aneurysms. European journal of radiology 2013; 82(10): 1598-1605.

53. Shi C, Awad IA, Jafari N, Lin S et al. Genomics of human intracranial aneurysm wall. Stroke 2009; 40(4): 1252-1261.

54. Aoki T, Nishimura M, Ishibashi R et al. Toll-like receptor 4 expression during cerebral aneurysm formation. Journal of neurosurgery 2011; 113(4): 851-858.

55. Liberato AC, Xu J, Montes D et al. Multivariable analysis on factors associated with aneurysm rupture in patients with multiple intracranial aneurysms. Emergency Radiology 2020; 27: 487-94.

56. Baldauf J, Kiwit J, Synowitz M. Cerebral aneurysms associated with von Recklinghausen's neurofibromatosis: Report of a case and review of the literature. Neurology India 2005; 53(2):213-16.

57. Onda $\mathrm{H}$, Kasuya $\mathrm{H}$, Yoneyama $\mathrm{T}$ et al. Genomewide-Linkage and Haplotype-Association Studies Map Intracranial Aneurysm to Chromosome 7q11. The American Journal of Human Genetics 2001; 69(4): 804-819.

58. Farnham JM, Camp NJ, Neuhausen SL et al. Confirmation of chromosome $7 \mathrm{q} 11$ locus for predisposition to intracranial aneurysm. Human Genetics 2001; 114(3): 250-255.

59. Ruigrok YM, Rinkel GJ. Genetics of Intracranial Aneurysms. Stroke 2008; 39(3): 1049-1055.

60. Yamada S, Utsunomiya M, Inoue K et al. Genome-Wide Scan for Japanese Familial Intracranial Aneurysms. Circulation 2004; 110(24): 3727-3733.

61. Krischek B, Inoue I. The genetics of intracranial aneurysms. Journal of Human Genetics 2006; 51(7): 587-594.

62. Yoneyama T, Kasuya H, Onda $\mathrm{H}$ et al. Association of positional and functional candidate genes FGF1, FBN2, and LOX on 5q31 with intracranial aneurysm. Journal of Human Genetics 2001; 48(6): 309-314.

63. Akagawa $\mathrm{H}$, Narita A, Yamada $\mathrm{H}$ et al. Systematic screening of lysyl oxidase-like (LOXL) family genes demonstrates that LOXL2 is a susceptibility gene to intracranial aneurysms. Human Genetics 2007; 121(3-4): 377-387.

64. Mineharu Y, Inoue K, Inoue S et al. Association analyses confirming a susceptibility locus for intracranial aneurysm at chromosome 14q23. Journal of Human Genetics 2008; 53(4): 325-332.

65. Olson JM, Vongpunsawad S, Kuivaniemi H et al. Search for intracranial aneurysm susceptibility gene(s) using Finnish families. BMC Medical Genetics 2002; 3(1).

66. Ozturk A K, Nahed BV, Bydon M et al. Molecular Genetic Analysis of Two Large Kindreds With Intracranial Aneurysms Demonstrates Linkage to 11q24-25 and 14q23-31. Stroke 2006; 37(4): 1021-1027.

67. Foroud T, Sauerbeck L, Brown R et al. Genome Screen to Detect Linkage to Intracranial Aneurysm Susceptibility Genes. Stroke 2008; 39(5): 1434-1440.

68. Foroud T, Koller DL, Lai D et al. Genome-Wide Association Study of Intracranial Aneurysms Confirms Role of Anril and SOX17 in Disease Risk. Stroke 2012; 43(11): 2846-2852.

69. Helgadottir A, Thorleifsson G, Magnusson KP et al. The same sequence variant on 9p21 associates with myocardial infarction, abdominal aortic aneurysm and intracranial aneurysm. Nature Genetics 2008; 40(2): 217-224.

70. Zhu G, Montgomery GW, James MR et al. A genome-wide scan for naevus count: Linkage to CDKN2A and to other chromosome regions. European Journal of Human Genetics 2006; 
15(1): 94-102.

71. Beatty BG, Qi S, Pienkowska M et al. Chromosomal Localization of Phospholipase A2 Activating Protein, an Ets2 Target Gene, to 9p21. Genomics 2009; 62(3): 529-532.

72. Mccolgan P, Thant KZ, Sharma, P. The genetics of sporadic ruptured and unruptured intracranial aneurysms: A genetic meta-analysis of 8 genes and 13 polymorphisms in approximately 20,000 individuals. Journal of Neurosurgery 2010; 112(4): 714-721.

73. Yasuno K, Bilguvar K, Bijlenga $\mathrm{P}$ et al. Genome-wide association study of intracranial aneurysm identifies three new risk loci. Nature Genetics 2010; 42(5): 420-425.
74. Markus HS. Stroke genetics. Human molecular genetics 2011; 20(R2): R124-R131.

75. Adib-Samii P, Brice G, Martin, RJ. Clinical spectrum of CADASIL and the effect of cardiovascular risk factors on phenotype: study in 200 consecutively recruited individuals. Stroke 2010; 41(4): 630-634.

76. Markus HS. Stroke genetics: prospects for personalized medicine. BMC medicine 2012; 10(1), 113.

77. Wang L, McLeod HL, Weinshilboum RM. Genomics and drug response. New England Journal of Medicine 2011; 364(12): 1144-1153. 